\title{
Modelling of Kealey Ice Rise, Antarctica, reveals stable ice-flow conditions in East Ellsworth Land over millennia
}

\author{
Carlos MARTíN, G. Hilmar GUDMUNDSSON, Edward C. KING \\ British Antarctic Survey, Natural Environment Research Council, Cambridge, UK \\ E-mail: cama@bas.ac.uk
}

\begin{abstract}
Flow at ice divides, their shape, size and internal structure depend not only on local conditions, but also on the flow regimes and past histories of the surrounding ice masses. Here we use field data from Kealey Ice Rise, Ellsworth Land, West Antarctica, in combination with flow modelling to investigate any possible signs of transients in the flow of the surrounding ice masses. Kealey Ice Rise shows linear surface features running parallel to its ridge in satellite imagery and a conspicuous layering in the ground-penetrating radar data known as double-peaked Raymond bumps. Through numerical modelling, by using an anisotropic full-Stokes thermomechanical flow solver, we analyse the evolution of Kealey Ice Rise and the timescales involved. We conclude that the features observed in the stratigraphy of Kealey Ice Rise require at least 3 ka of near-stationary flow conditions. However, we cannot exclude the possibility of a recent flow reorganization in the last century. We stress that the signs of stationary flow in radar stratigraphy observed in Kealey Ice Rise have been observed in other ice divides in the East Ellsworth Land area, suggesting stationary flow conditions over a millennial timescale in the region.
\end{abstract}

KEYWORDS: anisotropic ice flow, glacial rheology, ice-sheet modelling

\section{INTRODUCTION}

East Ellsworth Land (EEL), an area of the West Antarctic ice sheet (WAIS) south of the Antarctica Peninsula, flows into the Ronne Ice Shelf. There are a number of ice streams in this area, Evans Ice Stream and Rutford Ice Stream (RIS) being the largest, and in between them the smaller Carlson and Talutis Inlets. While flow of these ice streams and of the Ronne Ice Shelf itself is strongly affected by tides (Gudmundsson, 2011; Makinson and others, 2012), repeated GPS measurements over 25 years have failed to show any decadal changes in flow velocity on RIS (Gudmundsson and Jenkins, 2009). Vaughan and others (2008) suggested there had been a flow reorganization in RIS and Carlson Inlet $>240$ years $\mathrm{BP}$, but internal radar data contradict this claim, showing that Carlson Inlet has been stagnant for at least $6 \mathrm{ka}$ (King, 2011). Here we adduce further evidence from an icedivide analysis suggesting near-stationary flow conditions in this area over timescales of a few thousand years.

The central idea in this work is that if the stratigraphy of an ice divide is in steady state, there is a strong indication that the flow in surrounding areas has been stationary for, at least, a time comparable to the stratigraphy evolution timescale of the ice divide. Martín and others (2009) and Martín and Gudmundsson (2012) showed that an ice divide evolving towards a steady state develops an internal stratigraphy dominated by a prominent combination of synclines and anticlines known as double-peaked Raymond bumps, while at the same time linear dips running parallel to the ridge form at the surface. Furthermore, Martín and others (2009) showed that these features are reproduced assuming, and only assuming, anisotropic nonlinear flow.

Ice is known to be a highly anisotropic material (e.g. Pimienta and others, 1987). The crystals that constitute meteoric ice are randomly oriented, and macroscopic ice behaves as an isotropic material; but under certain conditions, ice flow and recrystallization processes create preferred orientations for the crystals and ice behaves as an anisotropic material. The evolution of crystal orientation fabric (COF) has been analysed from ice-core samples (e.g. Siple Dome (Di Prinzio and others, 2005), Byrd (Alley and others, 1995) and GRIP (Greenland Ice Core Project; Thorsteinsson and others, 1997)), but there is no direct measurement of the horizontal variation of COF in ice divides, and our knowledge of its horizontal variation is based on the interpretation of radar reflections (e.g. Matsuoka and others, 2003; Eisen and others, 2007) or inverse modelling of radar layers (e.g. Pettit and others, 2007; Drews and others, 2013).

In general, ice flow in a divide area is dominated by horizontal stretching and vertical compression. This flow regime induces a fabric that varies from isotropic at the surface, to a vertical girdle in the top half of the thickness, to a vertical single-maximum fabric (Alley and others, 1995). Recrystallization processes, mainly polygonization and migration, also affect the COF (e.g. Thorsteinsson, 2002; Gagliardini and others, 2009).

In addition to the effects of ice fabric on flow, it is particularly important in divides to consider the nonlinearity of ice rheology. One of the consequences of nonlinear flow is the formation of a relatively stiff zone of ice close to the bed (Raymond, 1983). This effect produces, after a time comparable to the characteristic time of the divide (ice thickness divided by accumulation rate), the formation of synclines in the radar stratigraphy known as Raymond bumps (e.g. Conway and others, 1999; Martín and others, 2009), and Martín and Gudmundsson (2012) showed that if the divide stays under stationary ice-flow conditions for a time comparable to several characteristic times, subtle evolution of flow-induced fabric produces the development of anticlines that are superimposed on the Raymond synclines. As a conseqence, the Raymond bump splits into two, leading to the formation of 'double-peaked Raymond bumps'. 


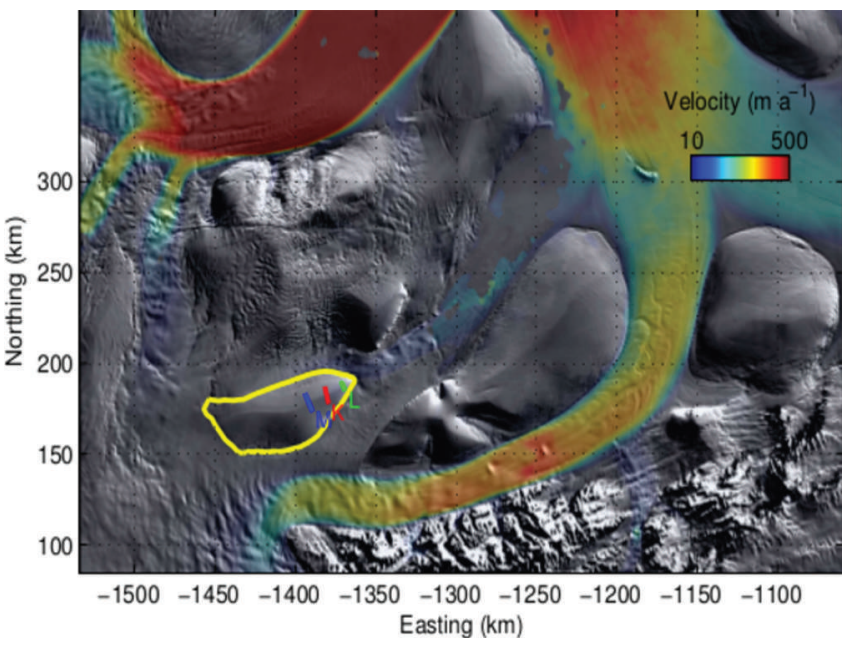

Fig. 1. MODIS Mosaic of Antarctica (MOA) image map (Haran and others, 2005), showing the Ellsworth Land area around Kealey Ice Rise (delineated in yellow). The fast-flowing areas are highlighted from Rignot and others' (2011) velocity map. The locations of ground-penetrating radar (GPR) profiles $\mathrm{M}, \mathrm{K}$ and $\mathrm{L}$ are shown in blue, red and green, respectively.

Different models of anisotropic rheology have been proposed in the past (e.g. Lliboutry, 1993; Castelnau and others, 1996; Mangeney and others, 1997; Thorsteinsson, 2001; Gödert, 2003; Gillet-Chaulet, 2007; Pettit and others, 2007; Castelnau and others, 2008). All these models differ in various details with regard to the crystal model used (Schmid law; a basal slip system model; transversely isotropic), the description of the fabric (discrete or continuous through an orientation distribution function or an orientation tensor) and in the homogenization procedure used (uniform strainrate, uniform stress or intermediate self-consistent procedures). A detailed review of all these models is provided by Gagliardini and others (2009).
The model we use is described in Martín and others (2009) and Martín and Gudmundsson (2012), but we summarize its main aspects in Appendices A-E for convenience. It incorporates a nonlinear extension to the flow-induced anisotropic rheology described by Gödert (2003) and Gillet-Chaulet (2007).

The objective of this paper is twofold. Firstly, we provide new evidence of stationary flow conditions on the EEL area on the century to millennium timescale from the surface and internal stratigraphy of the area. To that end, we model flow and internal stratigraphy of Kealey lce Rise and we look for signs of transient flow behaviour. Secondly, we use these data to validate our modelling approach and analyse the uncertainty in our model free parameters.

\section{DATA}

Kealey Ice Rise is located north of the junction of Talutis Inlet and Carlson Inlet, at the southwest side of the Ronne Ice Shelf. A GPS and radio-echo sounding survey was carried out during the 1996/97 austral summer with a pulseEKKO 100 ground-based radar system. The radar surveys were conducted using a central frequency of $25 \mathrm{MHz}$, and the data processed using the processing software Reflexw (http:// www.sandmeier-geo.de/GPR.html). The GPS data were collected using a number of Trimble 4000 and Leica 1200 units and processed using kinematic Precise Point Positioning technique with the Bernese GPS processing software (Dach and others, 2007).

The main profile locations are shown in Figure 1, and the radargrams $M, K$ and $L$ are shown in Figure 2. In the deepest areas of the ridge (profile $M$ ), the radar was unable to acquire the bedrock topography and we used BEDMAP bed topography (Lythe and others, 2001).

In addition to the geometry of the divides, we use the mean snow accumulation from Arthern and others (2006), and the mean surface temperature from Comiso (2000) (see Table 1).
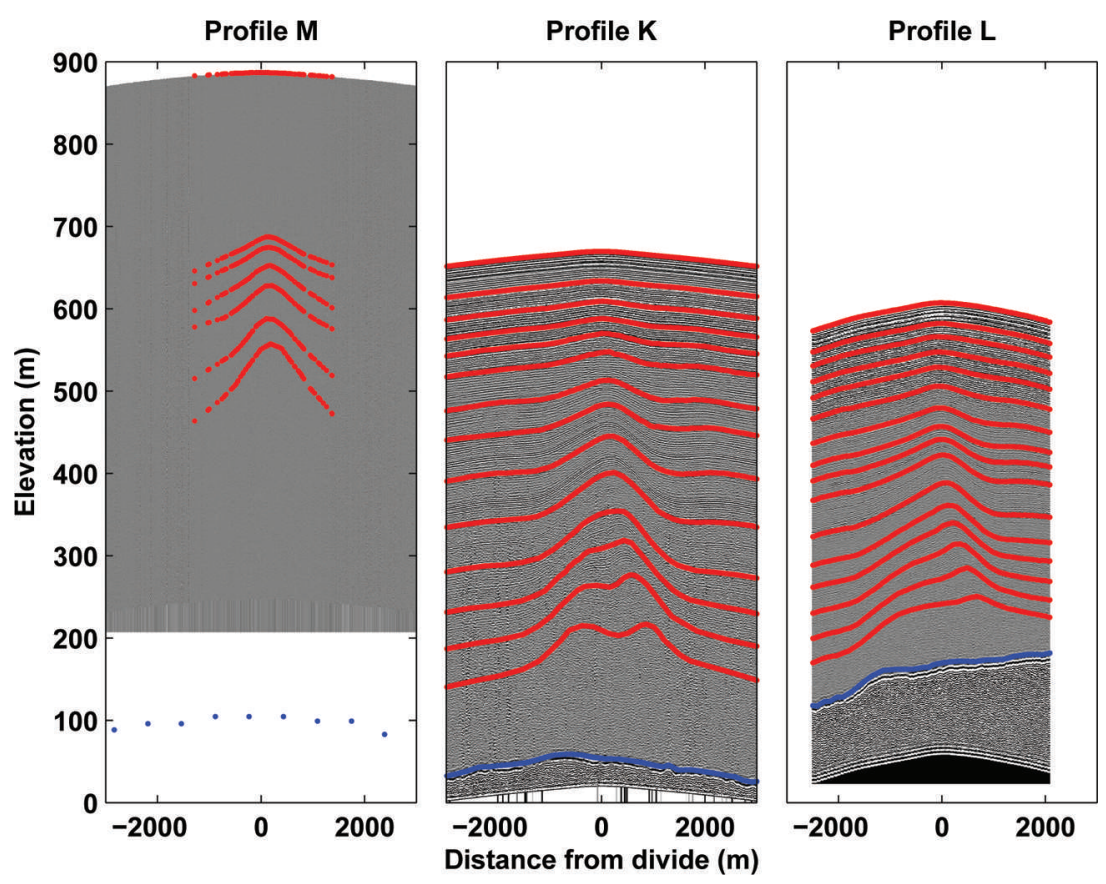

Fig. 2. GPR profiles $M, K$ and $L$ at Kealey Ice Rise (see Fig. 1 for location). Some internal horizons are highlighted in red and the bedrock topography in blue. The bedrock topography in profile M was extracted from BEDMAP bed topography (Lythe and others, 2001). 
Table 1. Numerical values of the parameters used in the simulations

\begin{tabular}{lcc}
\hline & Parameter & Value \\
\hline Flow & $a$ & $0.44 \mathrm{~m} \mathrm{a}^{-1}$ \\
& $\theta_{\mathrm{s}}$ & $-30{ }^{\circ} \mathrm{C}$ \\
Heat & $Q_{\mathrm{G}}$ & $50 \mathrm{~m} \mathrm{~W} \mathrm{~m}^{-2}$ \\
Rheology & $\alpha$ & 1 \\
& $\beta$ & {$[0.05,0.2]$} \\
& $\gamma$ & 1 \\
& $n$ & {$[2,3,4]$} \\
\hline
\end{tabular}

\section{NUMERICAL MODELLING}

The lack of both laboratory and in situ measurements makes detailed validation of the rheology more difficult (Appendix C). Martín and others (2009) and Martín and Gudmundsson (2012) determined values for rheological parameters of the model for which the qualitative observed features (e.g. the number of synclines or anticlines in the ice stratigraphy) are reproduced. In this section, we use the radargrams from Kealey Ice Rise to further validate and tune the model.

We use a transient full-Stokes thermomechanical solver and a nonlinear flow-induced anisotropic rheology that is described in Martín and Gudmundsson (2012) as an extension of Martín and others (2009). We reproduce the main details of the numerical model in Appendix $E$ for convenience.

\subsection{Model parameters}

The key parameters entering our rheology model are the two relative viscosities $\beta$ and $\gamma$, and the rheological index $n$ (Appendix C). $\gamma$ is the ratio of the viscosity in compression or tension along the $c$-axis to that in the basal plane, and is assumed to be close to unity (Gillet-Chaulet and others, 2006). In this study we therefore only vary the two parameters $\beta$, the ratio of viscosity of the grain for shear parallel to the basal plane to that in the basal plane, and $n$, the rheological index.

The laboratory experiments by Pimienta and others (1987) show that ice exhibiting a single-maximum fabric is ten times

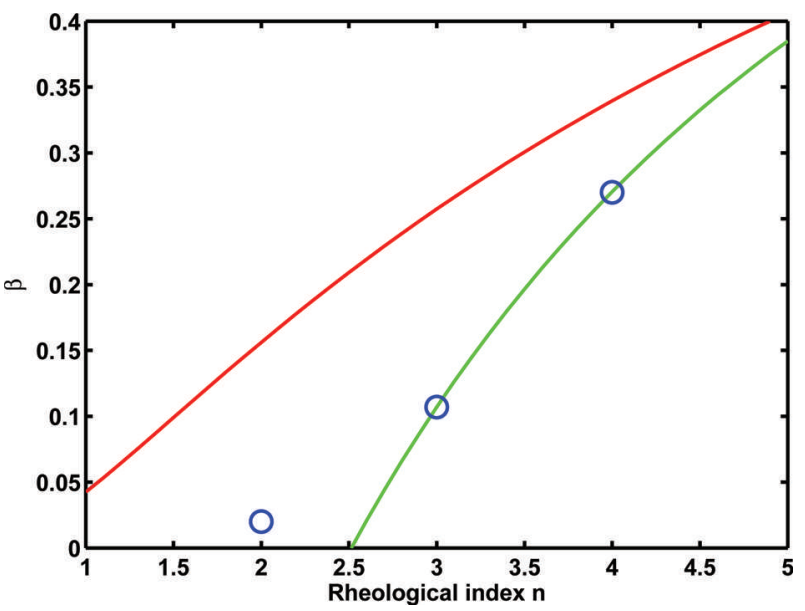

Fig. 3. Representation of the laboratory experiments by Pimienta and others (1987) in the model parameter space. The parameters are the rheological index $n$ and the relative viscosity $\beta$. The red line represents the result that ice with single-maximum fabric is ten times softer to deform perpendicularly to the $c$-axis than isotropic ice, and the green line that ice exhibiting a single-maximum fabric is ten times harder to deform in the $c$-axis direction than the isotropic ice. The blue circles represent the values used in this study.

softer to deform perpendicularly to the $c$-axis than isotropic ice, and ten times harder to deform in the $c$-axis direction than isotropic ice. With the rheology described in Appendix $C$, the enhancements for shear $E_{\mathrm{s}}$ and compression $E_{\mathrm{c}}$ for a single-maximum fabric with respect to an isotropic fabric are

$$
E_{\mathrm{s}}=\frac{2}{5}+\frac{3}{5} \beta, \quad \text { and } \quad E_{\mathrm{c}}=\frac{2}{5} \frac{1}{\beta}+\frac{3}{5}
$$

Figure 3 shows the values of $n$ and $\beta$ that, using the rheology described in Appendix $C$, follow the experimental results of Pimienta and others (1987), i.e. $E_{\mathrm{S}}=(1 / 10)^{1 / n}$ and $E_{\mathrm{C}}=10^{1 / n}$.

In order to understand the effect of $n$ and $\beta$ on the ice stratigraphy, we show in Figure 4 the isochrone layering for different parameter values. We chose the values $n=2,3,4$ and the corresponding values of $\beta$ so that the resulting pair is consistent with the shearing experiments of Pimienta and others (1987). The values of $n$ and $\beta$ chosen are shown in Figure 3 .
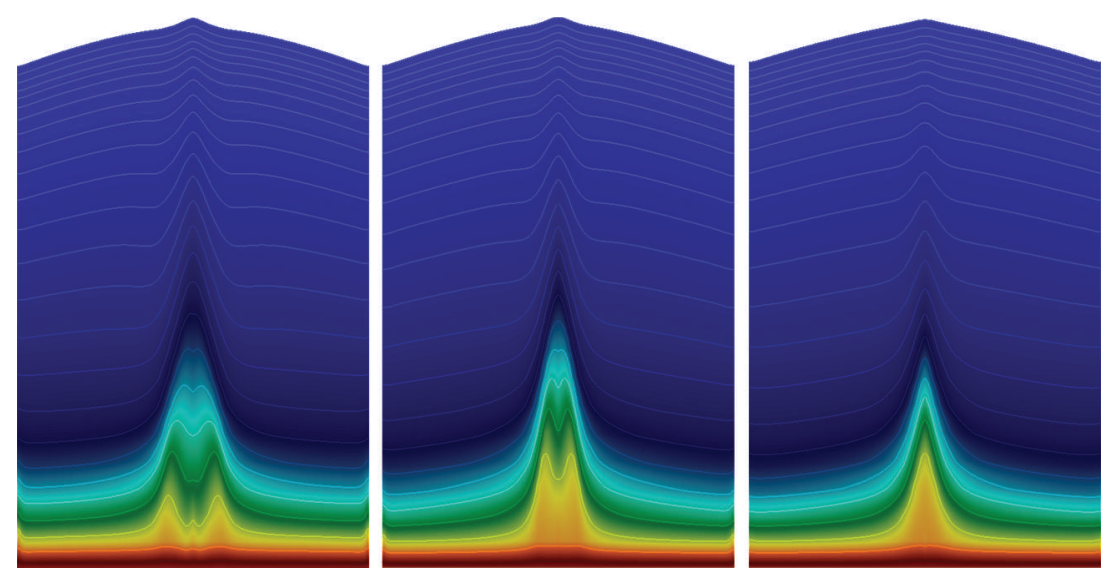

Fig. 4. Steady-state ice stratigraphy (isochrones) for an ice divide over a flat bedrock for different values of the rheological index $n$ and relative viscosity $\beta$. The parameters chosen are shown in Figure 3 . They are $n=2$ and $\beta=0.02$ in the left panel, $n=3$ and $\beta=0.10$ in the central panel and $n=4$ and $\beta=0.27$ in the right panel. 

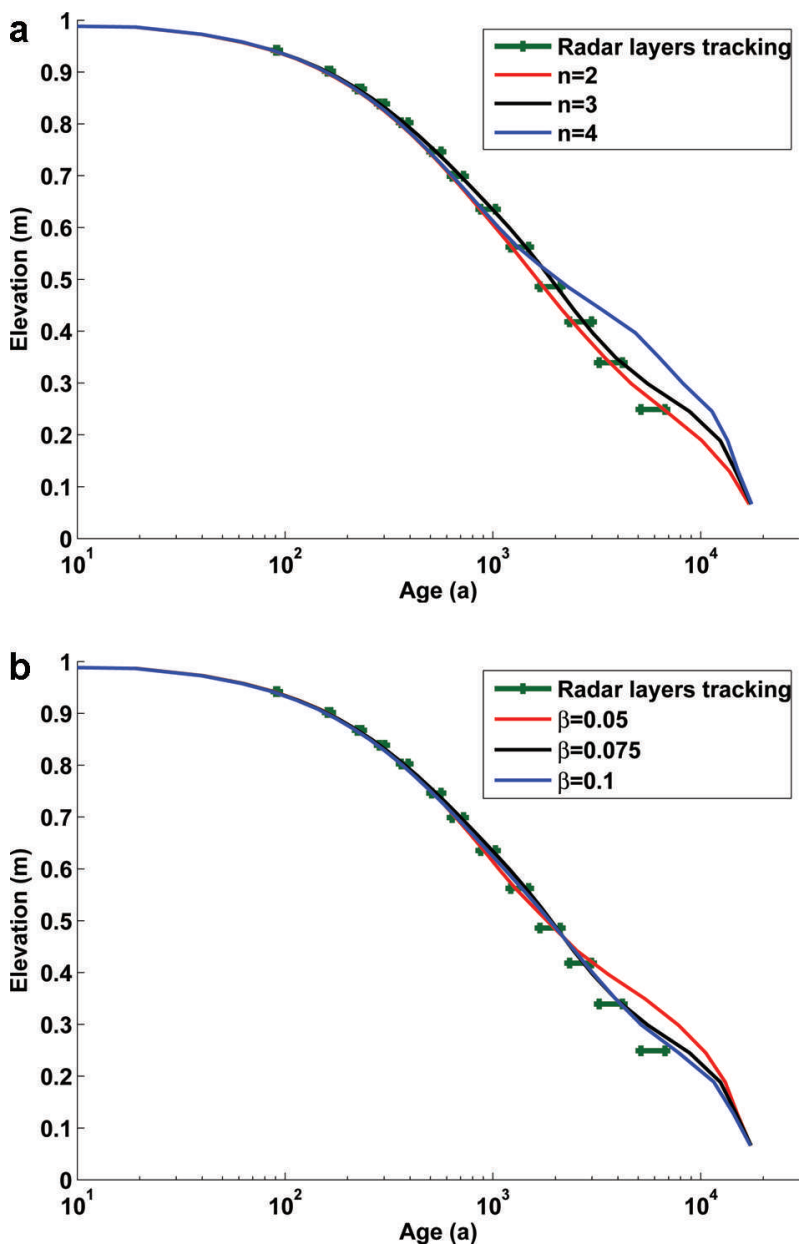

Fig. 5. Sensitivity of age versus depth distribution to (a) rheological index $n$ and (b) relative viscosity $\beta$. Solid lines represent the agedepth distribution predicted by the model using $\beta=0.1$ for the sensitivity analysis of $n$, and $n=3$ for the sensitivity analysis of $\beta$. We compare the modelled age vs depth distribution at the divide with the estimated age of the picked radar reflecting horizons. We estimate the age of radar horizons at the margins where the effect of flow and fabric evolution is minimal (Martín and Gudmundsson, 2012), and represent the horizontal variation of the one-dimensional age estimates along the radar layers as an interval.

\subsection{Modelling profiles $M, K$ and $L$ of Kealey Ice Rise}

We show here that the present stratigraphy of Kealey Ice Rise can be reproduced assuming that Kealey Ice Rise has been stationary for a period of, at least, several times the

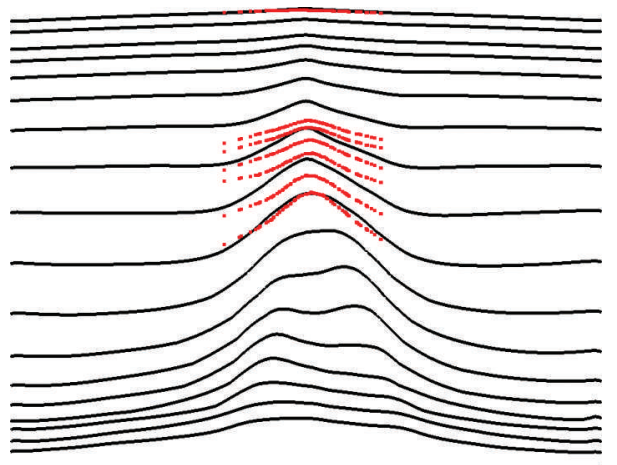

Fig. 6. Modelled isochrones (black) and radar layers (red) at profile $M$ (see Fig. 1). $n=3$ and $\beta=0.1$.

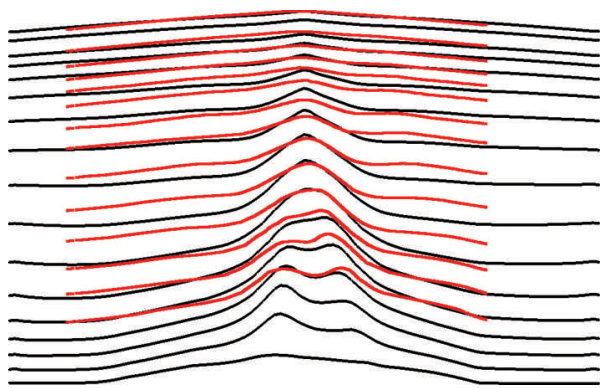

Fig. 7. Modelled isochrones (black) and radar layers (red) at profile $\mathrm{K}$ (see Fig. 1). $n=3$ and $\beta=0.1$.

characteristic time of the divide $\left(t_{\mathrm{D}}\right)$, ice thickness divided by accumulation. We model the transversal profiles $M, K$ and $\mathrm{L}$ (Figs 1 and 2).

We initialize the models with the present geometry, fabric linearly varying from isotropic at the surface to vertically aligned single-maximum at the base, temperature following Robin's (1955) analytical approximation, and age distributed as the steady-state solution assuming anisotropic shallow-ice approximation flow (Appendix D). As discussed in Martín and others (2009), the initial conditions affect the solution in the first stages of the divide development but not the steady state. The model parameters are provided in Table 1.

In order to study the impact of the free parameters $n$ and $\beta$ on modelled internal stratigraphy, we consider profile K, for which the best data on bedrock geometry are available. This is also the profile most closely corresponding to a plane-flow situation (Section 2). For given values of $n$ and $\beta$ we simulate the evolution of flow, fabric, temperature and surface topography towards steady state. We stop the simulation at $t=10 t_{\mathrm{D}}$ because, after that, changes in ice age only occur in a small layer, of $\sim 2.5 \%$ of the ice thickness, close to the bedrock.

Parameters $n$ and $\beta$ are not fully independent, and the modelled isochrones and radar horizons are difficult to compare due to the complex flow regime in the area and the bedrock topography. Our approach is to compare the modelled age vs depth distribution at the divide with the estimated age of the picked radar reflecting horizons. We estimate the age of radar horizons at the margins where the effect of flow and fabric evolution is minimal (Martín and Gudmundsson, 2012). The sensitivity of the results with different values of $n$ and $\beta$ is shown in Figure 5 .

The results in Figure 5 show that the parameters $n$ and $\beta$ that best fit the data are in the range $2 \leq n<4$ and $0.05<\beta \leq 0.1$. We choose $n=3$ and $\beta=0.1$ as representative of these values.

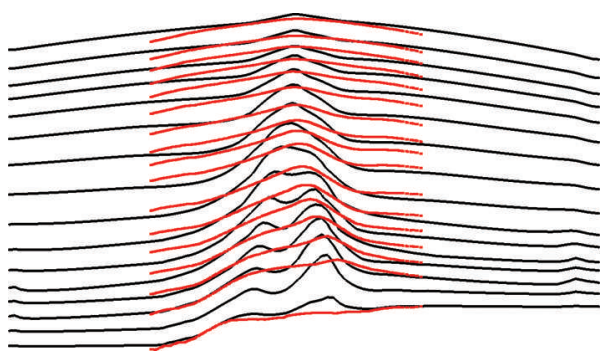

Fig. 8. Modelled isochrones (black) and radar layers (red) at profile L (see Fig. 1). $n=3$ and $\beta=0.1$. 
Finally, Figures 6-8 compare the modelled stratigraphy for profiles $M, K$ and $L$ with their respective radargrams for these values. The modelled steady-state stratigraphy for the three profiles shows double-peaked Raymond bumps, in agreement with the general case presented in Martín and Gudmundsson (2012). The model of profile K (Fig. 7) reproduces the qualitative observed features. In profile $M$ (Fig. 6) the radar was unable to acquire the deeper section of the profile. In profile L (Fig. 8) the radargram shows a single Raymond bump. Similar to the sensitivity analysis presented in Figure 5, there are small variations in the modelled stratigraphy within the range $2 \leq n<4$ and $0.05<\beta \leq 0.1$.

\section{DISCUSSION}

The results above (Section 3.2) show that our modelling approach reproduces the general features observed in the stratigraphy of profiles $M$ and $K$ of Kealey Ice Rise.

Kealey Ice Rise profiles $M$ and $K$ are relatively flat across the ridge: the across-ridge slope at a distance of one ice thickness from the divide (0.01) is larger than the along-ridge slope at the divide (0.005). As discussed in Martín and others (2009), we expect negligible influence of along-ridge flow in profiles $\mathrm{M}$ and $\mathrm{K}$ but not in $\mathrm{L}$, where the across-ridge slope at a distance of one ice thickness from the divide (0.01) is about the same as the along-ridge slope at the divide (0.01). Kealey Ice Rise profile $L$ does not show a two-dimensional steady-state stratigraphy, and this suggests either along-ridge flow or a recent or ongoing migration of that shallow section of the divide.

The values for the rheological parameters $n$ and $\beta$ that fit the data best are in the range $2 \leq n<4$ and $0.05<\beta<0.1$. These $n$ values are smaller than previous estimates by Martín and others (2006) and Hindmarsh and others (2011) who both found that $n=4$ gives the best fit to measurements of internal stratigraphy at Roosevelt Island and Fletcher Promontory, respectively. They are also smaller than the estimate of $n=4.5$ obtained by Gillet-Chaulet and others (2011) from in situ measurement of rheology at Summit, Greenland.

We stress, however, that Martín and others (2006), GilletChaulet and others (2011) and Hindmarsh and others (2011) employed isotropic flow models, and the numerical values obtained for $n$ can therefore not be compared directly with values from anisotropic flow models such as used here. Our model optimized values for $\beta$ are, as discussed in Section 3.1, compatible with the laboratory measurements by Pimienta and others (1987). The sensitivity analysis presented in Figure 5 shows that our results are not particularly sensitive to the values of $n$ and $\beta$ within those ranges, but we stress that we are only able to reproduce observations by using an anisotropic nonlinear rheology.

It could be argued that the stationary flow conditions on Kealey Ice Rise and its surrounding ice masses are unique to this particular area, but the presence of double-peaked Raymond bumps in the stratigraphy of Fletcher Promontory (Gillet-Chaulet and others, 2011) and Raymond bumps in airborne radar data of Fowler Ice Rise (personal communication from J. Kingslake, 2013) suggest stationary ice-flow conditions on the millennia timescale for the area (Fig. 1).

\section{SUMMARY}

We have shown that Kealey Ice Rise, a divide situated between Rutford and Evans Ice Streams, has not been subjected to large-scale flow reorganization over a period of at least twice the characteristic time of the divide $(\sim 2.8 \mathrm{ka}$ at profile $\mathrm{K})$. We find that we can successfully reproduce internal flow features (e.g. single and double Raymond bumps), as well as surface topographic features (e.g. the lineations running on both sides parallel to the ridge of the ice divide), without the need to resort to changes in external forcing with time. Hence, all these observed features of Kealey Ice Rise can be explained assuming stationary flow conditions over the past $\sim 3 \mathrm{ka}$.

We furthermore argue that near-stationary flow conditions are required for the formation of the internal and surface structures seen in the data from Kealey Ice Rise. The doublepeaked Raymond bumps can only develop given sufficient time (comparable to or longer than the characteristic time), and their existence therefore implies stationary flow conditions over these timescales. The small tilt visible in the data can, as discussed above, be explained as a consequence of the bed topography. Had the ice divide migrated horizontally by a distance more than a few times the ice thickness over the past few thousand years, this would have left a clear signature in the alignment of the Raymond bumps. Such a signature is not seen in the data. Hence, we can conclusively exclude the possibility of any significant ice-divide migration over the past few thousand years.

Finally we point out that the double-peaked Raymond bumps on the stratigraphy of Kealey Ice Rise are seen widely on other ice divides in the area. This suggests that not just Kealey Ice Rise but the whole of EEL has been nearstationary over recent millennia.

Our modelling approach uses a nonlinear flow-induced anisotropic rheology. In agreement with Martín and others (2009) and Martín and Gudmundsson (2012), we find that the qualitative behaviour of divide development and the timescales involved are not affected by the particular details of the rheology as long as we consider a nonlinear rheology $(n>1)$ and flow-induced anisotropy. The best model fit to observed internal stratigraphy of the Kealey Ice Rise is obtained using a rheological index in the range $2-4$ and for a relative anisotropic viscosity ratio $\beta$ in the range $0.05<\beta<0.1$.

\section{ACKNOWLEDGEMENTS}

We thank the scientific editor, Ralf Greve, and two anonymous reviewers for comments that helped to improve the quality of this paper.

\section{REFERENCES}

Advani SG and Tucker CL (1990) Closure approximations for three dimensional structure tensors. J. Rheol., 34(3), 367-386 (doi: 10.1122/1.550133)

Alley RB, Gow AJ and Meese DA (1995) Mapping C-axis fabrics to study physical processes in ice. J. Glaciol., 41(137), 197-203

Arthern RJ, Winebrenner DP and Vaughan DG (2006) Antarctic snow accumulation mapped using polarization of $4.3 \mathrm{~cm}$ wavelength microwave emission. J. Geophys. Res., 111(D6), D06107 (doi: 10.1029/2004JD005667)

Castelnau O, Duval P, Lebensohn R and Canova GR (1996) Viscoplastic modeling of texture development in polycrystalline ice with a self-consistent approach: comparison with bound estimates. J. Geophys. Res., 101(B6), 13 851-13868 (doi: 10.1029/96JB00412)

Castelnau O, Duval P, Montagnat M and Brenner R (2008) Elastoviscoplastic micromechanical modeling of the transient 
creep of ice. J. Geophys. Res., 113(B11), B11203 (doi: 10.1029/ 2008JB005751)

Chung DH and Kwon TH (2002) Invariant-based optimal fitting closure approximation for the numerical prediction of flowinduced fiber orientation. J. Rheol., 46(1), 169-194 (doi: 10.1122/1.1423312)

Comiso JC (2000) Variability and trends in Antarctic surface temperatures from in situ and satellite infrared measurements. J. Climate, 13(10), 1674-1696 (doi: 10.1175/1520-0442 (2000)013<1674:VATIAS > 2.0.CO;2)

Conway H, Hall BL, Denton GH, Gades AM and Waddington ED (1999) Past and future grounding-line retreat of the West Antarctic ice sheet. Science, 286(5438), 280-283 (doi: 10.1126/science.286.5438.280)

Dach R, Hugentobler U, Fridez P and Meindl M eds. (2007) Bernese GPS Software, Version 5.0. Astronomical Institute, University of Bern, Bern

Dahl-Jensen D (1989) Steady thermomechanical flow along twodimensional flow lines in large grounded ice sheets. J. Geophys. Res., 94(B8), 10355-10 362 (doi: 10.1029/JB094iB08p10355)

DiPrinzio CL, Wilen LA, Alley RB, Fitzpatrick JJ, Spencer MK and Gow AJ (2005) Fabric and texture at Siple Dome, Antarctica. J. Glaciol., 51(173), 281-290 (doi: 10.3189/ 172756505781829359)

Drews R, Martín C, Steinhage D and Eisen O (2013) Characterizing the glaciological conditions at Halvfarryggen ice dome, Dronning Maud Land, Antarctica. J. Glaciol., 59(213), 9-20 (doi: 10.3189/2013JoG12J134)

Eisen O, Hamann I, Kipfstuhl S, Steinhage D and Wilhelms F (2007) Direct evidence for continuous radar reflector originating from changes in crystal-orientation fabric. Cryosphere, 1(1), 1-10

Gagliardini O and Meyssonnier J (1999) Analytical derivations for the behaviour and fabric evolution of a linear orthotropic ice polycrystal. J. Geophys. Res., 104(B8), 17797-17809 (doi: 10.1029/1999JB900146)

Gagliardini O and Meyssonnier J (2002) Lateral boundary conditions for a local anisotropic ice-flow model. Ann. Glaciol., 35, 503-509 (doi: 10.3189/172756402781817202)

Gagliardini O, Gillet-Chaulet F and Montagnat M (2009) A review of anisotropic polar ice models: from crystal to ice-sheet flow models. In Hondoh T ed. Physics of ice core records II. (Supplement Issue of Low Temperature Science 68) Hokkaido University Press, Sapporo, 149-166

Gagliardini $\mathrm{O}$ and 14 others (2013) Capabilities and performance of Elmer/lce, a new-generation ice sheet model. Geosci. Model Dev., 6(4), 1299-1318 (doi: 10.5194/gmd-6-1299-2013)

Gillet-Chaulet F (2007) Modélisation de l'écoulement de la glace polaire anisotrope et premières applications au forage de Dome C. (Thèse de doctorat, Université Joseph Fourier)

Gillet-Chaulet F, Gagliardini O, Meyssonnier J, Montagnat M and Castelnau O (2005) A user-friendly anisotropic flow law for icesheet modelling. J. Glaciol., 51(172), 3-14 (doi: 10.3189/ 172756505781829584)

Gillet-Chaulet F, Gagliardini O, Meyssonnier J, Zwinger T and Ruokolainen J (2006) Flow-induced anisotropy in polar ice and related ice-sheet flow modelling. J. Non-Newtonian Fluid Mech., 134(1-3), 33-43 (doi: 10.1016/j.jnnfm.2005.11.005)

Gillet-Chaulet F, Hindmarsh RCA, Corr HFJ, King EC and Jenkins A (2011) In-situ quantification of ice rheology and direct measurement of the Raymond Effect at Summit, Greenland using a phase-sensitive radar. Geophys. Res. Lett., 38(24), L24503 (doi: 10.1029/2011GL049843)

Gödert G (2003) A mesoscopic approach for modelling texture evolution of polar ice including recrystallization phenomena. Ann. Glaciol., 37, 23-28 (doi: 10.3189/172756403781815375)

Greve R and Blatter H (2009) Dynamics of ice sheets and glaciers. Springer, Dordrecht

Gudmundsson GH (2011) Ice-stream response to ocean tides and the form of the basal sliding law. Cryosphere, 5(1), 259-270 (doi: 10.5194/tc-5-259-2011)
Gudmundsson $\mathrm{GH}$ and Jenkins A (2009) Ice-flow velocities on Rutford Ice Stream, West Antarctica, are stable over decadal time-scales. J. Glaciol., 55(190), 339-344 (doi: 10.3189/ 002214309788608697)

Haran T, Bohlander J, Scambos T and Fahnestock M (2005) MODIS mosaic of Antarctica (MOA) image map. National Snow and Ice Data Center, Boulder, CO. Digital media: http://nsidc.org/data/ nsidc-0280.html

Hindmarsh RCA, King EC, Mulvaney R, Corr HFJ, Hiess G and Gillet-Chaulet $F$ (2011) Flow at ice-divide triple junctions: 2. Three-dimensional views of isochrone architecture from icepenetrating radar surveys. J. Geophys. Res., 161(F2), F02024 (doi: 10.1029/2009JF001622)

Hutter K (1983) Theoretical glaciology; material science of ice and the mechanics of glaciers and ice sheets. D. Reidel, Dordrecht/ Terra Scientific, Tokyo

King EC (2011) Ice stream or not? Radio-echo sounding of Carlson Inlet, West Antarctica. Cryosphere, 5(4), 907-916 (doi: 10.5194/ tc-5-907-2011)

Lliboutry LA (1987) Very slow flows of solids: basics of modeling in geodynamics and glaciology. Martinus Nijhoff, Dordrecht

Lliboutry L (1993) Anisotropic, transversely isotropic nonlinear viscosity of rock ice and rheological parameters inferred from homogenization. Int. J. Plasticity, 9(5), 619-632 (doi: 10.1016/ 0749-6419(93)90023-J)

Lythe MB, Vaughan DG and BEDMAP consortium (2001) BEDMAP: a new ice thickness and subglacial topographic model of Antarctica. J. Geophys. Res., 106(B6), 11335-11351 (doi: 10.1029/2000JB900449)

Ma Y, Gagliardini O, Ritz C, Gillet-Chaulet F, Durand G and Montagnat M (2010) Enhancement factors for grounded ice and ice shelves inferred from an anisotropic ice-flow model. J. Glaciol., 56(199), 805-812 (doi: 10.3189/ 002214310794457209)

Makinson K, King MA, Nicholls KW and Gudmundsson GH (2012) Diurnal and semidiurnal tide-induced lateral movement of Ronne Ice Shelf, Antarctica. Geophys. Res. Lett., 39(10), L10501 (doi: 10.1029/2012GL051636)

Mangeney A and Califano F (1998) The shallow ice approximation for anisotropic ice: formulation and limits. J. Geophys. Res., 103(B1), 691-706 (doi: 10.1029/97JB02539)

Mangeney A, Califano F and Hutter K (1997) A numerical study of anisotropic, low Reynolds number, free surface flow for ice sheet modeling. J. Geophys. Res., 102(B10), 22 749-22 764 (doi: 10.1029/97JB01697)

Martín C and Gudmundsson GH (2012) Effects of nonlinear rheology, temperature and anisotropy on the relationship between age and depth at ice divides. Cryosphere, 6(5), 1221-1229 (doi: 10.5194/tc-6-1221-2012)

Martín C, Hindmarsh RCA and Navarro FJ (2006) Dating ice flow change near the flow divide at Roosevelt Island, Antarctica, by using a thermomechanical model to predict radar stratigraphy. J. Geophys. Res., 111(F1), F01011 (doi: 10.1029/2005JF000326)

Martín C, Gudmundsson GH, Pritchard HD and Gagliardini O (2009a) On the effects of anisotropic rheology on ice flow, internal structure, and the age-depth relationship at ice divides. J. Geophys. Res., 114(F4), F04001 (doi: 10.1029/2008JF001204)

Martín C, Hindmarsh RCA and Navarro FJ (2009b) On the effects of divide migration, along-ridge flow, and basal sliding on isochrones near an ice divide. J. Geophys. Res., 114(F2), F02006 (doi: 10.1029/2008JF001025)

Matsuoka K and 6 others (2003) Crystal orientation fabrics within the Antarctic ice sheet revealed by a multipolarization plane and dual-frequency radar survey. J. Geophys. Res., 108(B10), 2499 (doi: 10.1029/2002JB002425)

Meyssonnier J and Philip A (1996) A model for the tangent viscous behaviour of anisotropic polar ice. Ann. Glaciol., 23, 253-261

Pettit EC, Thorsteinsson T, Jacobson HP and Waddington ED (2007) The role of crystal fabric in flow near an ice divide. J. Glaciol., 53(181), 277-288 (doi: 10.3189/172756507782202766) 
Pimienta P, Duval Pand Lipenkov VY (1987) Mechanical behavior of anisotropic polar ice. IAHS Publ. 170 (Symposium at Vancouver 1987 - The Physical Basis of Ice Sheet Modelling), 57-66

Raymond CF (1983) Deformation in the vicinity of ice divides. J. Glaciol., 29(103), 357-373

Rignot E, Mouginot J and Scheuchl B (2011) Ice flow of the Antarctic Ice Sheet. Science, 333(6048), 1427-1430 (doi: 10.1126/science.1208336)

Robin GdeQ (1955) Ice movement and temperature distribution in glaciers and ice sheets. J. Glaciol., 2(18), 523-532 (doi: 10.3189/002214355793702028)

Thorsteinsson T (2001) An analytical approach to deformation of anisotropic ice-crystal aggregates. J. Glaciol., 47(158), 507-516 (doi: 10.3189/172756501781832124)

Thorsteinsson T (2002) Fabric development with nearest-neighbor interaction and dynamic recrystallization. J. Geophys. Res., 107(B1), 2014 (doi: 10.1019/2001JB000244)

Thorsteinsson T, Kipfstuhl J and Miller H (1997) Textures and fabrics in the GRIP ice core. J. Geophys. Res., 102(C12), 26 583-26599 (doi: 10.1029/97JC00161)

Vaughan DG, Corr HFJ, Smith AM, Pritchard HD and Shepherd A (2008) Flow-switching and water piracy between Rutford Ice Stream and Carlson Inlet, West Antarctica. J. Glaciol., 54(184), 41-48 (doi: 10.3189/002214308784409125)

\section{APPENDIX A. FIELD EQUATIONS AND BOUNDARY CONDITIONS}

We solve flow in an $x-z$ plane orthogonal to the axis of an ice divide. The $z$-axis is aligned vertically, the $x$-axis represents the horizontal direction of flow and in the $y$ direction we assume plane strain. The ice surface and bed are given by $z=s(x, t)$ and $z=b(x)$ respectively.

The Stokes system and its boundary conditions are (Greve and Blatter, 2009)

$$
\begin{aligned}
& \partial_{x} u+\partial_{z} w=0, \quad b(x) \leq z \leq s(x, t), \\
& \left.\begin{array}{l}
\partial_{x} \sigma_{x x}+\partial_{z} \sigma_{x z}=0 \\
\partial_{x} \sigma_{x z}+\partial_{z} \sigma_{z z}=\rho g
\end{array}\right\}, \quad b(x) \leq z \leq s(x, t), \\
& (\overrightarrow{\boldsymbol{\sigma}} \cdot \vec{n}) \cdot \vec{n}=0, \quad z=s(x, t), \\
& u=w=0, \quad z=b(x) \text {. }
\end{aligned}
$$

Equation (A1a) expresses the conservation of mass, and Eqn (A1b) the conservation of momentum. Here $\sigma$ is the Cauchy stress tensor, $\rho$ is the density of ice, $g$ is the vertical component of the gravitational acceleration, and $\vec{v}=(u, 0, w)$ is the velocity vector. Equations (A1c) and (A1d) are the boundary conditions at the surface and bed respectively. At the lateral boundaries we assume for the velocity field the anisotropic shallow-ice approximation. This approximation is discussed in Appendix D.

The kinematic boundary condition at the surface is

$$
\partial_{t} s+u \partial_{x} s=w+a \quad z=s(x, t),
$$

where $a$ is accumulation rate of ice, expressed as a volume rate per unit area.

The heat equation and boundary conditions are

$$
\begin{aligned}
\rho c\left(\partial_{t} \theta+\vec{v} \cdot \vec{\nabla} \theta\right)=\kappa \nabla^{2} \theta+Q_{\mathrm{D}}, & b(x)<z<s(x, t), \\
\theta-\theta^{\mathrm{s}}=0, & z=s(x, t), \\
-\kappa \vec{\nabla} \theta \cdot \vec{n}=Q_{\mathrm{G}}, & z=b(x),
\end{aligned}
$$

where $\theta^{\mathrm{s}}$ is the prescribed surface temperature, $\kappa$ is the thermal diffusivity of ice, $c$ is the specific heat capacity, $Q_{\mathrm{D}}=\operatorname{trace}(\boldsymbol{S} \cdot \boldsymbol{D})$ is the dissipation power, $\boldsymbol{D}$ and $\boldsymbol{S}$ are the strain-rate and deviatoric-stress tensors, $K$ is the thermal conductivity and $Q_{\mathrm{G}}$ is the geothermal heat flux. We assume that the horizontal gradient of temperature is zero at the lateral margins.

Isochrones are lines connecting ice particles of equal age $\Psi$, where age is calculated from

$$
\begin{array}{ll}
\partial_{t} \Psi+u \partial_{x} \Psi+w \partial_{z} \Psi=1, & b(x) \leq z \leq s(x, t), \\
\Psi=0, & z=s(x, t) .
\end{array}
$$

\section{APPENDIX B. ICE FABRIC: DESCRIPTION AND EVOLUTION}

To describe the ice fabric we use the second- and fourthorder orientation tensors, $\mathbf{a}^{(2)}$ and $\mathbf{a}^{(4)}$ respectively (e.g. Gödert, 2003; Gillet-Chaulet and others, 2006). We assume that the ice fabric is primarily induced by deformation rather than recrystallization. In that case, following Gödert (2003) and Gillet-Chaulet and others (2006) the evolution of the second-order orientation tensor $\mathbf{a}^{(2)}$ and boundary conditions can be written as

$$
\begin{array}{rlr}
\frac{\boldsymbol{D a}{ }^{(2)}}{\boldsymbol{D} t} & =\boldsymbol{W} \mathbf{a}^{(2)}-\mathbf{a}^{(2)} \boldsymbol{W} & b(x) \leq z \leq \\
& -\left(\boldsymbol{C a}^{(2)}+\mathbf{a}^{(2)} \boldsymbol{C}\right)+2 \mathbf{a}^{(4)}: \boldsymbol{C} & \\
\boldsymbol{a}^{(2)}= & \frac{1}{3} \boldsymbol{I}, & z=s(x, t),
\end{array}
$$

where $\boldsymbol{W}$ is the spin tensor (the skew-symmetric part of the gradient tensor),

$$
\boldsymbol{C}=(1-\alpha) \boldsymbol{D}+\alpha \frac{1}{2 \eta_{0}} \boldsymbol{S},
$$

and $\alpha$ is the interaction parameter. $\alpha$ controls the relative weighting of the strain-rate tensor $(\boldsymbol{D})$ and the deviatoricstress tensor (S) in the fabric-evolution equation (Eqn (B1)).

The evolution of the second-order orientation tensor $\mathbf{a}^{(2)}$ given by Eqn (B1) depends on $\mathbf{a}^{(4)}$, and for that reason the system of equations listed above is not closed. A common approach for obtaining a closed system is to express the components of the fourth-order orientation tensor as functions of those of the second-order orientation tensor (e.g. Advani and Tucker, 1990). We follow this approach and use the invariant-based closure approximation (IBOF). As shown by Chung and Kwon (2002), the general form of the IBOF closure approximation is

$$
\begin{aligned}
a_{i j k l}^{(4)}= & \beta_{1} \operatorname{Sym}\left(\delta_{i j} \delta_{k l}\right)+\beta_{2} \operatorname{Sym}\left(\delta_{i j} a_{k l}^{(2)}\right) \\
& +\beta_{3} \operatorname{Sym}\left(a_{i j}^{(2)} a_{k l}^{(2)}\right)+\beta_{4} \operatorname{Sym}\left(\delta_{i j} a_{k m}^{(2)} a_{m}^{(2)} l\right) \\
& +\beta_{5} \operatorname{Sym}\left(a_{i j}^{(2)} a_{k m}^{(2)} a_{m l}^{(2)}\right)+\beta_{6} \operatorname{Sym}\left(a_{i m}^{(2)} a_{m j}^{(2)} a_{k n}^{(2)} a_{n l}^{(2)}\right),
\end{aligned}
$$

where 'Sym' denotes the symmetrical part of its argument and $\beta_{i}$ are six functions of the second and third invariants of $\mathbf{a}^{(2)}$. Following Chung and Kwon (2002), we assume that $\beta_{i}$ are polynomials of degree 5 in the second and third invariant of $\mathbf{a}^{(2)}$, and we use the coefficients computed by Gillet-Chaulet and others (2006) so that $\mathbf{a}^{(4)}$ given by Eqn (B3) fits the fourth-order orientation tensor given by the orientation distribution function proposed by Gagliardini and Meyssonnier (1999). 


\section{APPENDIX C. RHEOLOGY}

We assume that the monocrystal grain behaves as a viscous transversely isotropic medium and that there is a uniform stress distribution within the polycrystal (uniform-stress or static model (e.g. Gagliardini and Meyssonnier, 1999; Thorsteinsson, 2001; Gödert, 2003). Following Gödert (2003) and Gillet-Chaulet and others (2005), we write the orthotropic rheology of the polycrystal as

$\boldsymbol{D}=\frac{1}{2 \eta_{0}}\left(\beta \boldsymbol{S}+\lambda_{1} \mathbf{a}^{(4)}: \boldsymbol{S}+\lambda_{2}\left(\boldsymbol{S} \cdot \mathbf{a}^{(2)}+\mathbf{a}^{(2)} \cdot \boldsymbol{S}\right)+\lambda_{3}\left(\mathbf{a}^{(2)}: \mathbf{S}\right) \boldsymbol{I}\right)$,

where $\boldsymbol{I}$ is the identity matrix, the symbols $\cdot$ and $\vec{?}$ denote the contracted product and the double contracted product, respectively, and the three $\lambda$ symbols are defined as

$$
\begin{array}{r}
\lambda_{1}=2\left(\beta \frac{\gamma+2}{4 \gamma-1}-1\right), \quad \lambda_{2}=(1-\beta) \\
\text { and } \lambda_{3}=-\frac{1}{3}\left(\lambda_{1}+2 \lambda_{2}\right) .
\end{array}
$$

The mechanical properties of the monocrystal can then be described by the basal shear viscosity $\eta_{0}$, and the two relative viscosity ratios $\beta$ and $\gamma$, i.e. $\beta$, the ratio of viscosity of the grain for shear parallel to the basal plane to that in the basal plane, and $\gamma$, the ratio of the viscosity in compression or tension along the $c$-axis to that in the basal plane (e.g. Lliboutry, 1987; Meyssonnier and Philip, 1996). The viscosity ratio parameter $\beta$ is known to be smaller than unity, and the parameter $\gamma$ to be close to unity (Gillet-Chaulet and others, 2006).

In accordance with Glen's flow law, we propose a nonlinear extension of the rheology described in Eqn (C1):

$$
\eta_{0}=\frac{1}{2} A(\theta)^{-\frac{1}{n}}\left(\frac{1}{2} \operatorname{tr}\left(\boldsymbol{D}^{2}\right)^{\frac{1-n}{2 n}}\right),
$$

where $A(\theta)$ is the rate factor and is temperature-dependent, $n$ is the rheological index and ' $\operatorname{tr}^{\prime}$ denotes trace. We use the Dahl-Jensen (1989) relationship for the rate factor,

$$
\begin{aligned}
A(\theta)= & \left(0.2071 \mathrm{e}^{0.5978 \theta_{c}}+0.09833 \mathrm{e}^{0.14747 \theta_{\mathrm{c}}}\right) \\
& \times 10^{-15} \mathrm{~Pa}^{-3} \mathrm{a}^{-1},
\end{aligned}
$$

with $n=3$ and $\theta_{\mathrm{c}}$ is the temperature $\left({ }^{\circ} \mathrm{C}\right)$.

Pettit and others (2007) and Ma and others (2010) propose a similar nonlinear extension to Glen's flow law (Eqn (C2)) that depends only on the stress tensor instead of on the strain-rate tensor. As observed by $\mathrm{Ma}$ and others (2010), no theoretical or experimental results are available that allow us to discard either of these solutions. We adopt the nonlinear extension described in Eqn (C9) because it reproduces qualitative aspects of the layering in the stratigraphy of a divide evolving towards steady state. Further numerical experiments (not reported here) showed that those observations cannot be reproduced using the model described above when using a nonlinear extension depending on the stress tensor only.

\section{APPENDIX D. ANISOTROPIC SHALLOW-ICE APPROXIMATION AND OUTFLOW BOUNDARY CONDITIONS}

Mangeney and Califano (1998) proposed the extension of the shallow-ice approximation (Hutter, 1983) for anisotropic ice. Its use as lateral boundary conditions in full-Stokes models is described by Gagliardini and Meyssonnier (2002). The zeroth-order shallow ice expansion approximates Eqns (A1a) and (A1b) as (Mangeney and Califano, 1998; Gagliardini and Meyssonnier, 2002)

$$
\begin{aligned}
\partial_{x} u+\partial_{z} w & =0, \\
\partial_{z}\left(\eta_{x z x z} \partial_{z} u\right) & =\rho g, \\
P & =\rho g(h-z),
\end{aligned}
$$

where $\eta_{x z x z}$ is, from Eqn (C1), the reduced component of the viscosity tensor linking strain-rate and stress shear components.

\section{APPENDIX E. NUMERICAL DETAILS}

The model presented in Appendices A-D is similar to that described in Martín and others (2009) aside from the coupling between heat equation and ice flow through the viscosity (Eqn (C2)) and the dissipation power (Eqn (A3a)). The numerical algorithms are, however, different.

The system represented by Eqns (A1-A4), with their respective boundary conditions, is solved with the opensource software Elmer/lce (http://elmerice.elmerfem.org/) (Gagliardini and others, 2013). The Stokes system, heat equation and free surface evolution are solved with the Elmer build-in finite-element solvers, using linear elements and stabilized with residual-free bubbles (see Elmer documentation for details). In contrast, fabric evolution and age equations are solved using a semi-Lagrangian method using a two-time-level scheme and linear interpolation (details in Martín and others, 2009). The reason for not using a finiteelement solver in the equations for fabric and age is that we find the semi-Lagrangian approach more stable close to the base of the divide where the ice is stagnant. 